\title{
Campilobacteriose genital bovina e tricomonose genital bovina: epidemiologia, diagnóstico e controle ${ }^{1}$
}

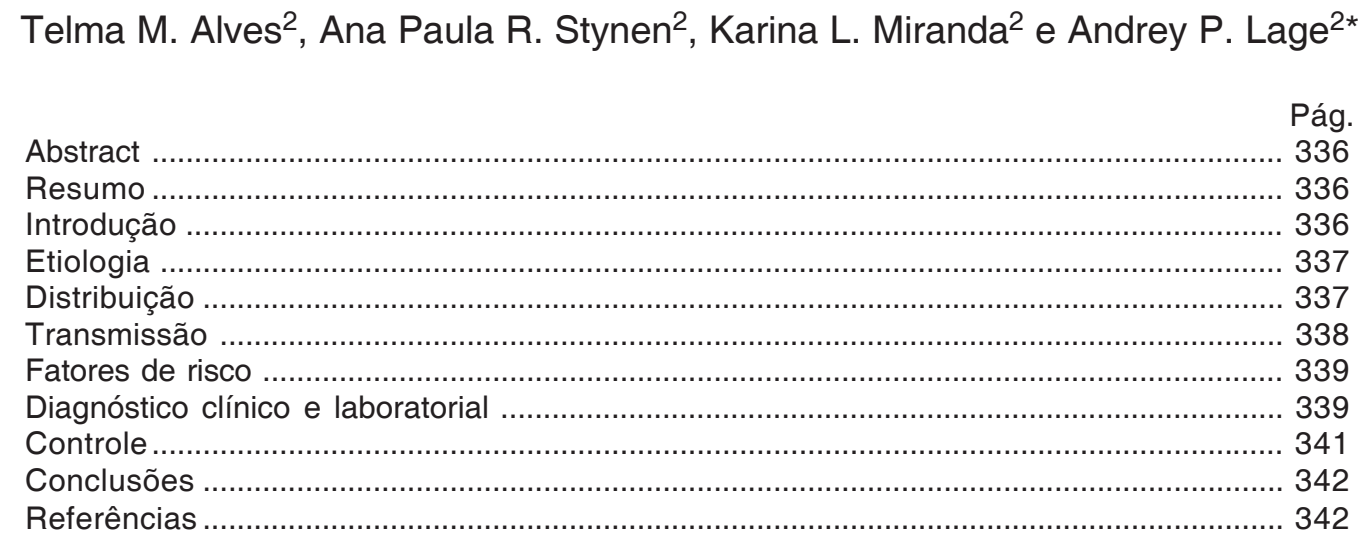

\begin{abstract}
Alves T.M,, Stynen A.P.R, Miranda K.L. \& Lage A.P. 2011. [Bovine genital campylobacteriosis and bovine genital trichomonosis: Epidemiology, diagnosis and control.] Campilobacteriose genital bovina e tricomonose genital bovina: epidemiologia, diagnóstico e controle. Pesquisa Veterinária Brasileira 31(4):336-344. Laboratório de Bacteriologia Aplicada, Departamento de Medicina Veterinária Preventiva, Escola de Veterinária, Universidade Federal de Minas Gerais. Av. Antônio Carlos 6627, Cx. Postal 567, Belo Horizonte, MG 30123-970, Brazil. E-mail: alage@ vet.ufmg.br

The present update deals with two of the most important sexually transmitted diseases of cattle: bovine genital campylobacteriosis and bovine genital trichomonosis. Epidemiological aspects, mainly their distribution in Brazil, alongside with their diagnosis in cattle are presented and commented. The main points in their diagnoses, including the description of the techniques and the interpretation of the results are also reviewed. Finally the control and prevention of both diseases are discussed.
\end{abstract}

INDEX TERMS: Campylobacter fetus subsp. venerealis, Tritrichomonas foetus, bovine genital campylobacteriosis, repeat breeding, abortion, vaccine.

RESUMO.- A presente atualização trata de duas das mais importantes doenças sexualmente transmitidas de bovinos, a campilobacteriose genital bovina e a tricomonose genital bovina. São abordados aspectos relacionados à epidemiologia destas doenças, principalmente em relação a sua distribuição no Brasil. Também são revisados aspectos importantes de diagnóstico, incluindo as técnicas

\footnotetext{
${ }^{1}$ Recebido em 9 de julho de 2010.

Aceito para publicação em 20 de setembro de 2010.

${ }^{2}$ Laboratório de Bacteriologia Aplicada, Departamento de Medicina Veterinária Preventiva, Escola de Veterinária, Universidade Federal de Minas Gerais (UFMG), Av. Antônio Carlos 6627, Cx. Postal 567, Belo Horizonte, MG 30123-970, Brasil. *Autor para correspondência: alage@vet.ufmg.br
}

e interpretação dos resultados, além de medidas de controle para ambas as doenças.

TERMOS DE INDEXAÇÃO: Campylobacter fetus subsp. venerealis, Tritrichomonas foetus, repetição de cio, aborto, vacina.

\section{INTRODUÇÃO}

A campilobacteriose genital bovina (CGB) e a tricomonose genital bovina (TGB) são doenças infecto-contagiosas de transmissão sexual, que acometem bovinos em idade reprodutiva e causam grandes perdas econômicas em decorrência dos problemas reprodutivos desencadeados (Dekeyser 1984, Goodger \& Skirrow 1986). Podem causar morte embrionária, repetição de cios, abortos, vacas vazias no final da estação de monta, necessidade de maior frequên- 
cia na reposição de touros, aumento do período entre partos e, consequentemente, queda na produção de bezerros nascidos e produção de leite (Stoessel 1982, Pellegrin et al. 2002). Nos países onde ocorrem, estas doenças causam grandes perdas anuais uma vez que levam a média de $60 \%$ de taxa de retorno ao cio e que apenas 35\% das novilhas cobertas ficam prenhes (McCool et al. 1988).

As características epidemiológicas e clínicas, as alterações dos índices zootécnicos e as principais manifestações da infecção causada pelo Campylobacter fetus subsp. venerealis e pelo Tritrichomonas foetus são muito semeIhantes, o que permite que vários aspectos das doenças e das estratégias de controle da infecção possam ser discutidos conjuntamente.

\section{ETIOLOGIA}

Campylobacter fetus possui duas subespécies, C. fetus subsp. fetus, que causa aborto esporádico em bovinos e infertilidade enzoótica em ovinos, e $C$. fetus subsp. venerealis, causador da CGB. C. fetus subsp. venerealis é um bastonete Gram-negativo, espiralado, em forma de vírgula ou em "S", possui um ou dois flagelos polares e não forma esporos. É microaerófilo, necessitando de atmosfera rica em $\mathrm{CO}_{2}(10 \%)$ e reduzida concentração de $\mathrm{O}_{2}(5 \%)$ para seu crescimento (Vandamme 2000). $C$. fetus é classificado em dois sorotipos denominados A e B, com base na composição do lipopolissacarídeo da membrana externa da bactéria, sendo que $C$. fetus subsp. fetus apresenta ambos os sorotipos (A e B), enquanto $C$. fetus subsp. venerealis apresenta somente o sorotipo A (Thompson \& Blaser 2000).

Tritrichomonas foetus é um protozoário piriforme, anaeróbio facultativo, possui axóstilo que dá sustentação ao corpo e que se estende de uma ponta a outra, dando rigidez ao microrganismo. Possui três flagelos anteriores, um quarto flagelo posterior e uma membrana ondulante (Skirrow
\& BonDurant 1988). Pode se apresentar na forma de trofozoíto ou pseudocisto, sendo que o pseudocisto se refere à transformação morfológica em forma compactada, imóvel (Granger et al. 2000). Os sorotipos de T. foetus descritos (Brisbane, Belfast, e Manley) foram estabelecidos utilizando-se técnicas de aglutinação, hemaglutinação passiva e testes cutâneos e todos são patogênicos (Rae \& Crews 2006).

\section{DISTRIBUIÇÃO}

A CGB e a TGB possuem distribuição mundial, tendo sido detectadas em vários países. Dados recentes da OIE mostram a sua presença em países como África do Sul, Argentina, Austrália, Brasil, Canadá, Estados Unidos da América, França, Inglaterra e Nova Zelândia, dentre outros (OIE 2009) (Fig.1 e 2). Geralmente, áreas que utilizam a monta natural como estratégica reprodutiva de bovinos possuem alta prevalência de CGB e TGB (Lage 2001, BonDurant 2005).

No Brasil, a CGB e TGB possivelmente estão presentes em todos os estados da federação em função das práticas de manejo reprodutivo utilizadas no país. A CGB foi diagnosticada pela primeira vez no país em 1955 no Estado de São Paulo por D’Ápice (1956) (Quadro 1). Já para a TGB, o primeiro relato no Brasil foi em 1947 por Di Primio, Gloss e Roehe no Estado do Rio Grande do Sul (Roehe 1948) (Quadro 2). Desde então, vários relatos de suas ocorrências foram realizados nos diferentes estados do país. Quando tipificados fenotípica e molecularmente, a maioria dos isolados de $C$. fetus de abortos ou problemas reprodutivos em bovinos foi classificada como $C$. fetus subsp. venerealis (Vargas et al. 2003). A prevalência da CGB em bovinos de corte foi estimada em 2000, nos 12 estados com a maior produção de bovinos do país, em 19,7\% (IC 95\%: $13,3 \% ; 25,1 \%$ ) de animais infectados e em $50,8 \%$ (IC 95\%: 41,6\%; 60,1\%) de propriedades contaminadas (Miranda 2005). Entretanto, ambas as doenças permane-

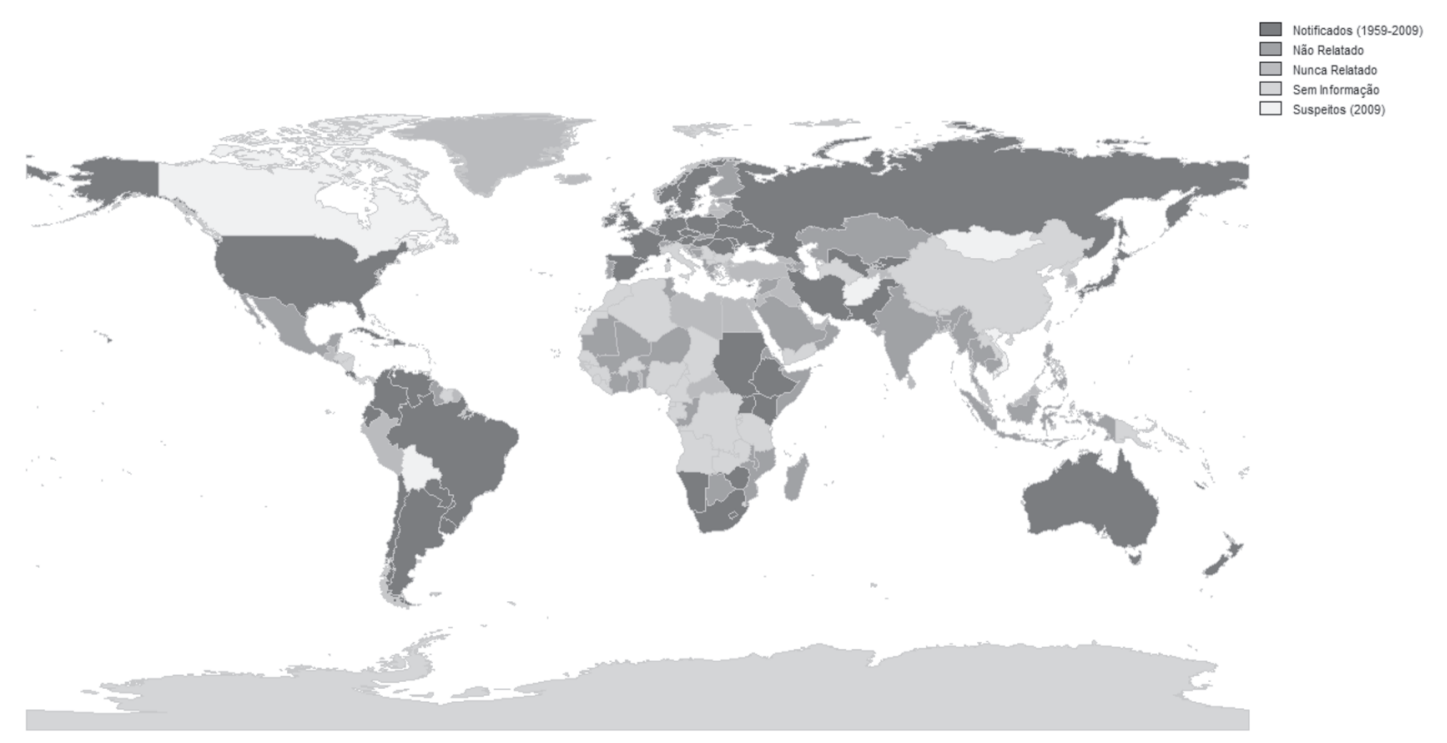

Fig.1. Distribuição da campilobacteriose genital bovina, segundo relatos dos países membros da Organização Mundial de Saúde Animal (OIE 2009). 


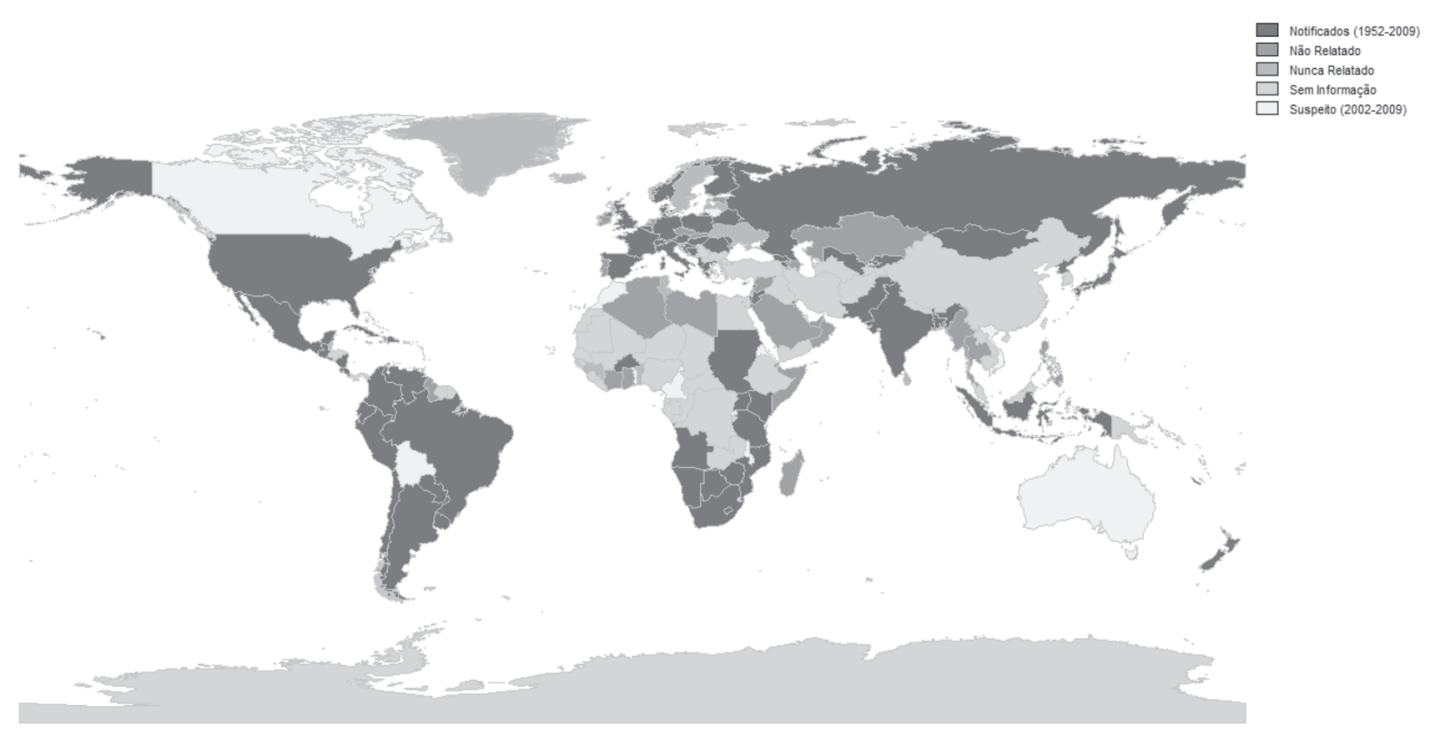

Fig.2. Distribuição da tricomonose genital bovina, segundo relatos dos países membros da Organização Mundial de Saúde Animal (OIE 2009).

Quadro 1. Campilobacteriose genital bovina em bovinos no Brasil, 1956-2009

\begin{tabular}{|c|c|c|c|c|}
\hline Ano & Estado $^{a}$ & Autores & $\begin{array}{l}\text { Método } \\
\text { de diag- } \\
\text { nóstico }\end{array}$ & $\begin{array}{c}\text { Índice } \\
(\%)\end{array}$ \\
\hline 1955 & SP & D’Apice(1956) & 1 & $1 \%$ relato \\
\hline $1960-1961$ & RJ & Guida et al.(1960) & MA & 3,5 \\
\hline 1960 & RS & Mies Filho(1960) & MA & 27,0 \\
\hline 1963 & RS & Mies Filho(1963) & MA & 53,8 \\
\hline 1967 & $\mathrm{SP}$ & Castro et al.(1967) & MA & 8,2 \\
\hline 1971 & $\mathrm{PR}, \mathrm{RS}, \mathrm{MG}$ & Castro et al.(1971) & MA & 8,0 \\
\hline 1976 & BA & Costa(1976) & MA & 66,9 \\
\hline $1974-1977$ & $M G$ & Leite(1977) & IFD & 28,9 \\
\hline $1969-1976$ & RJ & Ramos \& Guida(1978) & MA & 12,0 \\
\hline 1986 & SP & Genovez et al.(1986) & I & 23,9 \\
\hline 1976-1996 & $M G$ & Lage et al.(1997) & IFD & 27,9 \\
\hline 1995-1996 & MS & Pellegrin et al.(2002) & IFD & 52,3 \\
\hline $1996-1997$ & $M G$ & Jesus et al.(1999) & MA & 46,9 \\
\hline $1996-1997$ & RJ & Jesus et al.(1999) & MA & 22,3 \\
\hline $1996-1997$ & $M G$ & Jesus et al.(1999) & I & 16,7 \\
\hline $1996-1997$ & RJ & esus et al.(1999) & I & 42,3 \\
\hline 1998 & MG & Stynen et al.(2003) & IFD & 25,5 \\
\hline 2000 & $\begin{array}{l}\mathrm{BA}, \mathrm{GO}, \mathrm{MA}, \\
\mathrm{MT}, \mathrm{MS}, \mathrm{MG} \text {, } \\
\mathrm{PA}, \mathrm{PR}, \mathrm{RS}, \\
\mathrm{RO}, \mathrm{SP} \text { e TO }\end{array}$ & Miranda(2005) & IFD & 19,7 \\
\hline 2009 & RJ & Rocha et al. (2009) & IFD/I & 35,9 \\
\hline
\end{tabular}

a BA = Bahia, GO = Goías, MA = Maranhão, MT = Mato Grosso, MS = Mato Grosso do Sul, MG = Minas Gerais, PA = Pará, PR = Paraná, $\mathrm{RJ}=$ Rio de Janeiro, $\mathrm{RS}=$ Rio Grande do Sul, $\mathrm{RO}=$ Rondônia, $\mathrm{SP}=$ São Paulo e TO = Tocantins; ${ }^{b}$ IFD = Imunofluorescência direta, MA = Muco-aglutinação, I = isolamento. Fonte: Lage (2001), modificada.

cem subnotificadas no Brasil. A ausência de diagnóstico sistemático em todo o país, associado às dificuldades de envio e análise laboratorial de amostras clínicas e ao pequeno número de laboratórios com capacidade técnica para a realização do diagnóstico destas doenças fazem com que a real situação da CGB e TGB permaneça desconhecida da maioria dos técnicos e proprietários.
Quadro 2. Tricomonose genital bovina em bovinos no Brasil, 1953-2009

\begin{tabular}{|c|c|c|c|c|}
\hline Ano & Estado $^{a}$ & Autores & $\begin{array}{l}\text { Método } \\
\text { de diag- } \\
\text { nósticob }\end{array}$ & $\begin{array}{l}\text { Índice } \\
(\%)\end{array}$ \\
\hline 1947 & RS & Roehe(1948) & - & $1^{\circ}$ relato \\
\hline 1953-1954 & $\begin{array}{l}\text { CE, PB, } \\
\text { PE, BA, RJ }\end{array}$ & Mello(1954) & I & $7,3-9,0$ \\
\hline 1963 & $M G$ & Megale(1963) & I & $\begin{array}{l}1 \% \text { relato } \\
\text { em MG }\end{array}$ \\
\hline 1970 & SP & Amaral et al.(1970) & 1 & 8,0 \\
\hline 1971 & $M G$ & $\begin{array}{c}\text { Medeiros \& } \\
\text { Figueiredo(1971) }\end{array}$ & I & 14,4 \\
\hline 1981 & PB & Bacalhau(1981) & 1 & 27 \\
\hline 1991 & RS & Gomes et al.(1991) & 1 & 1,88 \\
\hline $1958-2001$ & RJ & Jesus et al.(2004) & i & 29 \\
\hline 1997 & $M G$ & Leite et al.(1997) & I & 5,9 \\
\hline 2009 & RJ & Rocha et al.(2009) & I & 0 \\
\hline
\end{tabular}

a $\mathrm{CE}=$ Ceará, $\mathrm{BA}=$ Bahia, $\mathrm{MG}=-$ Minas Gerais, $\mathrm{PB}=$ Paraíba, $\mathrm{RJ}=$ Rio de Janeiro, PE = Pernambuco, SP = São Paulo, RS = Rio Grande do Sul; ${ }^{\mathrm{b}}$ Método de diagnóstico, I = isolamento.

\section{TRANSMISSÃO}

A transmissão de Campylobacter fetus subsp. venerealis e de Tritrichomonas foetus se dá por via sexual e as fêmeas se infectam após a cópula com touro infectado ou viceversa, quando ocorre infecção em quase $100 \%$ dos casos. A principal forma de introdução da CGB e da TGB em um rebanho é pela aquisição de touros ou vacas infectados (Clark 1971, Stoessel 1982, Lage \& Leite 2000). Outras formas de infecção sexual são via sêmen contaminado e comportamento homossexual de touros, o que permite a transmissão de macho a macho. Transmissão por fômites - espéculos, material utilizado na coleta de sêmen e inseminação artificial, camas utilizadas em criações com alta densidade - também pode ocorrer, porém são menos frequentes (Wagner et al. 1965, Eaglesome \& Garcia 1997, Lage \& Leite 2000). 


\section{FATORES DE RISCO}

A CGB e a TGB ainda são doenças de difícil controle em países com grandes rebanhos bovinos, como o Brasil, onde o sistema de manejo dominante utiliza a monta natural. Por serem doenças sexualmente transmissíveis, com sinais clínicos pouco evidentes, quando a presença das doenças é constatada no rebanho, as perdas econômicas já são grandes. A entrada da CGB e da TGB em um rebanho ocorre quase sempre pela introdução de animais infectados, geralmente touros. A infecção se difunde rapidamente, permanecendo inaparente no início, geralmente pela falta de controle zootécnico dos rebanhos (Lage 2001).

No Brasil, somente são inseminadas artificialmente em torno de $6 \%$ das vacas em idade reprodutiva (Barbosa \& Machado 2008), predominando a monta natural, que é empregada na maior parte dos sistemas de produção extensivos, apresentando todos os fatores de risco na manutenção da CGB e da TGB em um rebanho, como ausência de protocolos sanitários na seleção dos touros, utilização de relação touro - vaca inadequadas, mascarando os problemas reprodutivos presentes no rebanho e deficiência na observação e detecção de cios, confirmação de gestação e abortos (Lage 2001, BonDurant 2005).

Outro problema encontrado é a presença de touros mais velhos, que tendem a exercer uma dominância sobre os mais jovens por ocasião da monta, o que faz aumentar o risco de transmissão da doença (Clark 1971, Barling et al. 1997, Rae \& Crews 2006). Outro ponto importante na epidemiologia dessas doenças é a utilização de touros de repasse, que podem estar infectados e manter a infecção em rebanhos que utilizam a inseminação artificial (Stynen et al. 2003).

\section{DIAGNÓSTICO CLÍNICO E LABORATORIAL}

O correto diagnóstico é o primeiro passo para a implantação de medidas de controle eficazes contra a CGB e a TGB. A observação das manifestações clínicas, do histórico dos animais e da avaliação dos dados zootécnicos da propriedade podem auxiliar no diagnóstico da infecção por Campylobacter fetus subsp. venerealis e por Tritrichomonas foetus. A principal manifestação clínica de ambas as doenças é a repetição cio em intervalos aumentados e irregulares (Stoessel 1982, BonDurante 2005). O intervalo de retorno ao cio pode variar, mas geralmente é superior a 35 dias (Clark 1971, Skirrow \& BonDurant 1988). Isto é decorrente da mortalidade embrionária que ocorre após a implantação do embrião, o que leva a um maior período entre um cio e outro (Alves, 2010).

Na TGB, as fêmeas podem apresentar corrimento vaginal purulento ao retornarem ao cio, em função de piometra causada pelo $T$. foetus (Parsonson et al. 1976). Característica importante dessa piometra, que pode ser encontrada em torno de $5 \%$ das vacas, é sua ocorrência no póscoito, o que sugere infecção por T. foetus (BonDurant 2005). Outra característica clínica que pode ajudar a diferenciar a TGB da CGB é que pode haver presença de maceração fetal na infecção por $T$. foetus enquanto a infecção por $C$. fetus subsp. venerealis pode produzir fetos mumificados (Stoessel 1982). No entanto, as lesões mais frequentemente encontradas no feto abortado são, na CGB, a brocopneumonia supurativa e hepatite intersticial, mas não são patognomônicas da doença (Bryner 1990). Já nos fetos abortados em decorrência da infecção pelo $T$. foetus é frequente o encontro de pneumonia piogranulomatosa com presença de células gigantes multinucleadas (Rhyan et al. 1988, Rhyan et al. 1995).

A maioria das fêmeas consegue eliminar a infecção após três a seis ciclos e podem então ficar gestantes (BonDurant 2005). Entretanto, várias vacas mantêm a infecção mesmo durante a gestação, o que pode ocasionar abortos e infecção vaginal após o parto (Cipolla et al. 1994, Corbeil et al. 1998). Abortos podem ocorrer em ambas as infecções, entre $5 \%$ a $10 \%$, sendo mais frequentes no terço médio da gestação - em torno do $4^{\circ}$ e $5^{\circ}$ mês de gestação, mas também podendo ocorrer em períodos mais tardios (Clark 1971, Rhyan et al. 1988, BonDurant 1990, Bryner 1990). A retenção de placenta também é ocorrência comum na CGB e TGB (Clark 1971, Stoessel 1982).

Vários parâmetros zootécnicos, além das altas taxas de retorno ao cio, estão alterados em rebanhos que possuem animais infectados por $C$. fetus subsp. venerealis ou por $T$. foetus. A idade à primeira cria é tardia em decorrência das novilhas serem mais suscetíveis à infecção por estes agentes, o que ocasiona maiores perdas nesta categoria animal (Stoessel 1982). Também, como consequência das repetições de cio, há um aumento do intervalo entre partos, pois são necessárias várias coberturas antes que as fêmeas adquiram imunidade e fiquem gestantes (BonDurant 2005). Ao final da estação, grande número de fêmeas, principalmente as novilhas estão vazias, acarretando aumento do período da estação de monta, com consequente aumento da estação de parição (Pellegrin et al. 2002). A taxa de natalidade também é baixa nos rebanhos com estas doenças em decorrência de que várias fêmeas não conseguem debelar a infecção e ficarem gestantes e dos abortos que podem ocorrer (Goodger \& Skirrow 1986).

Apesar dos sinais clínicos e do histórico dos animais e da propriedade indicarem a infecção por $C$. fetus subsp. venerealis e $T$. foetus, o diagnóstico laboratorial é fundamental, pois só ele pode confirmar qual o agente causador do problema observado no rebanho.

O material para o diagnóstico laboratorial da CGB e da TGB deve ser coletado preferencialmente dos touros, por estes estarem em menor número na propriedade, além de serem os grandes disseminadores da doença nos rebanhos (BonDurant 2005). Entretanto, o diagnóstico laboratorial também pode ser realizado em material coletado de fêmeas, de fetos abortados e de membranas fetais (Stoessel 1982, BonDurant 2005).

Nos machos pode ser coletado esmegma por raspador, pipeta de inseminação artificial ou lavado prepucial (Genovez et al. 1986, Fernandes \& Gomes 1992). O raspado é feito pela escarificação da mucosa do prepúcio e do pênis 
do touro utilizando um raspador ou uma pipeta de inseminação presa a uma seringa ou pera para puxar o esmegma coletado. O material coletado é então inoculado em meios de transporte específicos para $C$. fetus subsp. venerealis e T. foetus (Lander 1990, Lage et al. 1992, Appel et al. 1993). O lavado prepucial é realizado introduzindo-se cerca de $50 \mathrm{~mL}$ de solução salina tamponada no prepúcio, massageando-o com o óstio fechado por uma das mãos e recoletando-se o material por um sistema de sifão. Nas fêmeas, pode ser coletado muco cervico-vaginal com pipeta de inseminação ou tampão absorvente (Fernandes \& Gomes 1992, Stynen et al. 2003). Um aspecto importante a ser levado em conta é que os touros devem ser mantidos em repouso sexual por 7 a 15 dias antes da coleta do material e que três coletas, com os mesmos intervalos, permanecendo o animal em descanso sexual, devem ser realizadas para se aumentar a sensibilidade do diagnóstico (Stoessel 1982, Skirrow \& BonDurant 1988).

Parte do material coletado poderá ser utilizado para detecção de $C$. fetus subsp. venerealis e outra para a detecção de $T$. foetus. Para a detecção de $C$. fetus subsp. venerealis o material deverá ser transportado em meios de transporte e enriquecimento (TEM) que propiciam ambiente de microaerofilia adequado à sobrevivência do microrganismo e utilizam misturas de antibióticos para reduzir a flora bacteriana presente no prepúcio (Lander 1990, Lage et al. 1992). O material em TEM deve ser transportado a $4^{\circ} \mathrm{C}$ e colocado em estufa a $37^{\circ} \mathrm{C}$ para crescimento por até três dias. Neste período repiques são realizados em ágar infusão de cérebro e coração (Brain Heart Infusion), acrescido de $10 \%$ de sangue desfibrinado de equino, em condições de microaerofilia $\left(5 \% \mathrm{O}_{2}, 5 \% \mathrm{H}_{2}, 10 \% \mathrm{CO}_{2}\right.$ e $\left.80 \% \mathrm{~N}_{2}\right)$ a $37^{\circ} \mathrm{C}$ por $48 \mathrm{~h}$. As colônias pequenas e translúcidas são escolhidas para a realização da coloração de Gram e observação microscópica da morfologia espiralada característica das bactérias do gênero Campylobacter. Para se confirmar a identificação, testes bioquímicos são realizados, sendo os principais para se diferenciar $C$. fetus subsp. venerealis de $C$. fetus subsp. fetus a produção de $\mathrm{H}_{2} \mathrm{~S}$ em meio contendo cistina e a tolerância a 1\% de glicina, testes nos quais as subespécies são negativas e positivas paras ambos, respectivamente (Vandamme 2000). Além disto, a imunofluorescência direta (IFD) (Figueiredo et al. 2002) e a reação em cadeia da polimerase (PCR) também podem ser utilizadas (Hum et al. 1997, McMillen et al. 2006).

Por ser um microrganismo fastidioso, de difícil isolamento e identificação, outras técnicas diagnósticas foram desenvolvidas. A IFD é um teste que também pode ser utilizado para o diagnóstico direto da infecção por $C$. fetus subsp. venerealis. Sua sensibilidade analítica, ou seja, seu limite de detecção, foi estimado em $10^{2}$ bactérias $/ \mathrm{mL}$ (Figueiredo et al. 2002). O material coletado por lavado prepucial é submetido a duas centrifugações, sendo a primeira a $600 \mathrm{Xg}$, para a retirada de debris presentes no lavado, e a segunda a $13000 \mathrm{X}$ g, para sedimentação das bactérias presentes. O sedimento é fixado por acetona em lâmina para IFD e é utilizado um soro anti- $C$. fetus marca- do com fluoresceína para detecção do agente em microscopia de fluorescência (Figueiredo et al. 2002).

Outros testes estão sendo estudados para aplicação no diagnóstico da CGB como ensaio imunoenzimático (ELISA), desenvolvido para detecção de anticorpos da classe IgA no muco vaginal de fêmeas bovinas com suspeita de infecção pelo $C$. fetus. Esses anticorpos foram escolhidos porque persistem por mais tempo e sua concentração permanece constante no trato genital por muitos meses (Hewson et al. 1985, Hum et al. 1994). Brooks et al. (2004) utilizaram anticorpos monoclonais contra LPS de C. fetus, em ELISA direto, mas não obtiveram bom limite de detecção ( $10^{4}$ a $\left.10^{6} \mathrm{UFC} / \mathrm{mL}\right)$, tornando inviável a utilização da técnica com estes anticorpos monoclonais. Também foram desenvolvidos e são utilizados ensaios de PCR multiplex para diferenciar o $C$. fetus subsp. fetus do $C$. fetus subsp. venerealis (Hum et al. 1997) e PCR em tempo real com sondas específicas, também capazes de diferenciar as duas subespécies (McMillen et al. 2006).

Para a detecção de $T$. foetus, o material coletado deve ser inoculado e transportado em meio de transporte e enriquecimento de Diamond modificado, enriquecido com $10 \%$ de soro fetal bovino e mescla de antibióticos (penicilina e estreptomicina e anfotericina B) (Appel et al. 1993). Esse meio deve ser transportado à temperatura ambiente, protegido da luz e o mais rápido possível ao laboratório, pois o diagnóstico é dependente da viabilidade do microrganismo. Outros meios para transporte e cultivo de $T$. foetus também podem ser utilizados, como o meio de Rieck modificado (Guida et al. 1960), entretanto apresentam menor crescimento do agente. Em alguns países é possível se encontrar o InPouch TF test (BioMed Diagnostics, San Jose, CA, EUA), um meio de cultivo comercial para o transporte e crescimento de $T$. foetus em lâmina, desenvolvido nos Estados Unidos da América, que facilita o isolamento e identificação de $T$. foetus. Este sistema comercial é amplamente utilizado em condições de campo, com resultados consistentes e uma sensibilidade de 70 a $97 \%$ (Kvasnicka et al. 1996, Rae et al. 1999). Seu manuseio é fácil, porém seu custo é elevado e o mesmo não está disponível no Brasil atualmente.

As técnicas laboratoriais rotineiramente utilizadas para o diagnóstico da TGB são os métodos diretos de diagnósti$\mathrm{co}$, sendo o principal o isolamento e identificação dos microrganismos. No laboratório os meios de transporte e enriquecimento são incubados a $37^{\circ} \mathrm{C}$ por 7 a 10 dias, com observação diária do crescimento em microscopia de contraste de fase. A presença de protozoários móveis, de morfologia piriforme e com presença de três flagelos anteriores e um flagelo posterior deve ser confirmada pela coloração de Giemsa. Apesar da morfologia característica, deve-se realizar PCR para a diferenciação de $T$. foetus de outros protozoários que podem ocasionalmente estar presentes em material de prepúcio (Campero et al. 2003). As técnicas de PCR e PCR em tempo real também são utilizadas com sucesso para o diagnóstico direto da infecção por $T$. foetus em material clínico (BonDurant et al. 2003, McMillen \& Lew 2006). 


\section{CONTROLE}

A principal estratégia de controle da CGB e da TGB é a implantação na propriedade de um programa de inseminação artificial com sêmen de qualidade, visto que isto bloqueará a mais importante via transmissão das doenças, o contato sexual (BonDurant 2005). Entretanto, a inseminação artificial é difícil de ser empregada em grandes rebanhos de corte onde predomina o sistema de criação extensivo, em função do alto custo do processo e de dificuldades tecnológicas e de recursos humanos das propriedades.

O descarte dos touros portadores de Campylobacter fetus subsp. venerealis ou Trtrichomonas foetus, assim como a implantação de estação de monta limitada (60-90 dias) e descarte das fêmeas vazias ao final da mesma, e o repouso sexual por 3-4 ciclos para recuperação das fêmeas, também é preconizado no controle da CGB e da TGB (Stoessel 1982, Pellegrin et al. 2002, Rae \& Crews 2006). No entanto, como muitas fêmeas persistem infectadas por vários meses (Clark 1971, Rhyan et al. 1988, Cipolla et al. 1994, Rae \& Crews 2006), algumas mantendo a infecção por toda a gestação, essa estratégia não propicia a erradicação da CGB e TGB dos rebanhos, apesar de auxiliar em seu controle. Outra medida auxiliar no controle é se evitar a utilização de touros de repasse, pois estes podem constituir reservatórios da infecção (Stynen et al. 2003, BonDurant 2005).

A segregação de animais jovens para a formação de um rebanho livre dessas doenças sexualmente transmissíveis a partir de novilhas virgens e de touros não infectados seria ideal, mas é difícil de ser realizada na prática, porque é necessário que ocorra segregação total dos animais livres da infecção daqueles infectados. Na maioria dos sistemas de produção existentes no país, a manutenção desta separação total não é possível ou é economicamente inviável, resultando em infecção do rebanho segregado após alguns meses da implantação da estratégia (Lage 2001). No entanto, esta é a principal estratégia disponível para o controle da TGB no país.

Uma estratégia que pode se empregada, principalmente em animais doadores de sêmen e embrião, em receptoras ou em animais de maior valor zootécnico, em função dos custos, é o tratamento. Dentre os vários esquemas empregados no tratamento da CGB tem se conseguido bons resultados com o uso de dihidroestreptomicina na dosagem de $22-25 \mathrm{mg} / \mathrm{kg}$ por via parenteral no primeiro, terceiro e quinto dias de tratamento. No segundo e quarto dias de tratamento deve-se fazer aplicação de uma solução contendo $5 \mathrm{~g}$ de dihidroestreptomicina diretamente no pênis e prepúcio, realizando uma massagem vigorosa (Seger et al. 1966, Stossel 1982).

No caso da TGB, o tratamento tem se mostrado mais complicado em função do grande número de princípios ativos e esquemas de tratamento que têm sido preconizados. Alguns dos mais efetivos são o dimetridazole por via oral, o ipronidazole e o metronidazol por via parenteral e a acriflavina de uso tópico (McLoughlin 1970, Hidalgo et al. 1970, Palladino et al. 1982, Skirrow et al. 1985, Jesus et al. 1996). Em função dos custos, o uso de $50 \mathrm{~g}$ de creme neutro contendo acriflavina a $0,5 \%$ para o tratamento de cada touro, em aplicação única, parece ser viável (Pellegrin et al. 1998). Entretanto, o tratamento da TGB continua sendo um problema, pois não há disponibilidade de medicamentos veterinários com essas bases para este fim (Guest 1988, SINDAN 2010).

O sucesso do tratamento para ambas as doenças também é avaliado por três testes diagnósticos consecutivos, intervalados de 7-15 dias de repouso sexual, que devem todos apresentar resultados negativos (Skirrow \& BonDurant 1988).

A vacinação tem se mostrado bastante eficaz na prevenção das repetições de cio e abortos causados pelo $C$. fetus subsp. venerealis e T. foetus (Leite et al. 1980, BonDurant et al. 1993, Villarroel et al. 2004, BonDurant 2005). $A$ vacinação é uma forma eficiente de controlar a CGB e a TGB, principalmente em áreas onde a monta natural é muito utilizada. No entanto, há diferenças de eficácia entre as vacinas contra CGB e TGB.

Em rebanhos com infecção por $C$. fetus subsp. venerealis, fêmeas em idade reprodutiva devem ser vacinadas anualmente, em torno de 30 dias antes do início da entrada em reprodução (Dekeyser 1984, Stoessel 1982, BonDurant 2005). No caso de primovacinação, as novilhas e vacas devem receber duas doses, uma em torno de $60 \mathrm{e}$ outra em torno de 30 dias antes do início da cobertura. $O$ controle da CGB pelo emprego da vacinação em vacas é muito eficaz, mesmo em rebanhos que apresentam altas taxas de infecção (Clark et al. 1974, Leite et al. 1980, Eaglesome et al. 1986, Ramos et al. 1986). A relação custobenefício do controle da CGB empregando-se a vacinação das vacas é muito promissora, pois foi demonstrado que 0 retorno está próximo de 18 vezes os valores investidos na vacinação (Leite 1977).

Os resultados de utilização de vacinas contra a CGB em touros são controversos na literatura (Bouters et al. 1973, Van Aert et al. 1976, Vasquez et al. 1983, Fóscolo et al. 2005). Todavia, a vacinação de touros deve ser empregada, pois a utilização de duas doses de vacina aplicadas nos touros em intervalos de 23 dias eliminou a infecção de $C$. fetus subsp. venerealis de mais de $55 \%$ dos touros (Fóscolo et al. 2005). Assim, a vacinação de touros deve ser utilizada em conjunto com a vacinação das vacas, por aumentar a imunidade de rebanho, mas não deve ser preconizada como medida única do programa de controle.

Em contraste com os resultados de proteção próxima a $100 \%$ na vacinação contra CGB, a proteção conferida pelas vacinas com $T$. foetus se apresenta em níveis muito mais baixos, $45 \%$ de eficácia (Kvasnicka et al. 1992). No entanto, sua utilização é preconizada, pois reduz os prejuízos dos proprietários, pela diminuição do tempo de infecção e pelo aumento da taxa de parição (Kvasnicka et al. 1992, Sanderson \& Gnad 2002, BonDurant 2005).

BonDurant et al. (1993) testaram a imunização sistêmica em novilhas com um antígeno de superfície de $T$. foetus, o LPG TF1.17, eliminando o microrganismo em sete se- 
manas. Este antígeno tornou-se um bom candidato para uma vacina no combate da TGB.

Uma área de estudo na produção de vacinas contra patógenos do trato reprodutivo é a vacinação na mucosa genital. Como ambos os agentes infectam o trato genital, a resposta de anticorpos é predominantemente da classe $\operatorname{lgA}$. As mucosas estão em contato constante com o meio externo, possuem IgA com componente secretório (S-IgA) no epitélio e lâmina própria e contém folículos linfóides organizados na região subepitelial (Ogra 1996). Cobo et al. (2004) testaram uma vacina contendo os dois microrganismos, $C$. fetus subsp. venerealis e $T$. foetus, utilizando imunizações via sistêmica e via vaginal. Os resultados mostraram melhor desempenho da vacina quando comparado às vacinas utilizadas no mercado, que normalmente utilizam a via subcutânea de aplicação. A aplicação intravaginal da vacina é uma forma de incitar a produção de IgA no local onde ocorre a infecção, sendo IgA um anticorpo que perdura mais e é mais resistente que a IgG em infecções por patógenos do trato genital bovino (Corbeil 1999).

A proteção estimulada pela vacinação contra TGB é menor em touros, mas recentemente foi observado que a vacinação de touros induz imunidade sistêmica e local, o que leva à resistência ao desafio por $T$. foetus (Clark et al. 1983, Clark et al. 1984, Cobo et al. 2009). Desta forma a vacinação de touros também pode ser indicada junto à vacinação das novilhas e vacas.

Para se avaliar as vantagens da utilização de vacinas contra TGB, Villarroel et al. (2004) utilizaram um modelo matemático que considerou os principais fatores de risco para a infecção por $T$. foetus. As análises desse modelo verificaram que a vacinação de fêmeas contra TGB pode ser vantajosa quando não é possível o emprego de medidas que mitiguem os fatores de risco. Entretanto, quando a implantação de medidas que reduzam os fatores de risco for possível, estas se mostraram mais viáveis que a vacinação.

Em função das dificuldades de implementação de outras medidas de controle nas condições brasileiras, a utilização da vacinação poderia contribuir para o controle da TGB. No entanto, o mercado brasileiro ainda não conta com essas vacinas (SINDAN 2010).

\section{CONCLUSÃO}

A CGB e a TGB são doenças de alta prevalência nos rebanhos bovinos no Brasil e causam elevados prejuízos às cadeias produtivas do leite e da carne no país. Em função disso, devem ser estimuladas medidas que visem o correto diagnóstico dessas enfermidades para que se possa meIhorar a aquisição de animais destinados à reprodução e estabelecer medidas de controle adequadas que permitam a diminuição dos prejuízos e a erradicação dessas duas doenças sexualmente transmissíveis de bovinos.

Agradecimentos.- Ao Professor Renato de Lima Santos e à Professora Zélia Inês Portela Lobato pela leitura crítica do manuscrito. Ao Doutor
Carlos M. Campero pelas discussões relacionadas à infecção por Tritrichomonas foetus. À Juliana Pinto da Silva Mol, Giovanna Ivo Andrade e Ethiene Luiza de Souza Santos pelo auxílio com os mapas. Parte dos dados apresentados nesta revisão foi gerada com recursos da Fundação de Apoio à Pesquisa do Estado de Minas Gerais (Fapemig), do Conselho Nacional de Desenvolvimento Científico e Tecnológico (CNPq) e da Fundação de Estudo e Pesquisa em Medicina Veterinária e Zootecnia (FEPMVZ). T.M. Alves foi bolsista da Coordenação de Aperfeiçoamento de Pessoal de Nível Superior (Capes) e atualmente é bolsista do CNPq; A.P.R. Stynen e A.P. Lage são bolsistas do CNPq.

\section{REFERÊNCIAS}

Alves T.M. 2010. Participação dos receptores semelhantes ao Toll na indução de expressão de mRNA para CXCL8 (IL-8) na infecção in vitro de células epiteliais por Campylobacter fetus subsp. venerealis e Tritrichomonas foetus. Tese de Doutorado em Ciência Animal, Escola de Veterinária, Universidade Federal de Minas Gerais, Belo Horizonte, MG. 48p.

Amaral V., Santos S.M. \& Fenerich F.L. 1970. Levantamentos de incidência do Tritrichomonas foetus no estado de São Paulo. Biológico, São Paulo, 36:201-204.

Appel L., Mickelsen W.D., Thomas M.H. \& Harmon W.M. 1993. A comparison of techniques used for the diagnosis of Tritrichomonas foetus infections in beef bulls. Agri-practice 14(2):30-34.

Bacalhau A.S. 1981. Ocorrência da tricomonose em bovinos da bacia leiteira de Campinas Grande no estado da Paraíba. Revta Bras. Reprod. Anim. 5:21-24.

Barbosa R.T., Machado R. 2008. Panorama da inseminação artificial em bovinos. Documentos 84, Embrapa Pecuária Sudeste, São Carlos. 28p.

Barling K., Wikse S., Magee D., Thompson J. \& Field R. 1997. Management of beef bulls for high fertility. Compend. Contin. Educ. Pract. Vet. 19:888-893.

BonDurant R.H. 1990. Abortion/infertility caused by Tritrichomonas foetus, p.161-164. In: Kirkbride C.A. (Ed.), Laboratory Diagnosis of Livestock Abortion in Food Animals. lowa State University Press, Ames.

BonDurant R.H. 2005. Venereal diseases of cattle: Natural history, diagnosis, and the role of vaccines in their control. Vet. Clin. North Am., Food Anim. Pract. 21:383-408

BonDurant R.H., Corbeil R.R. \& Corbeil L.B. 1993. Immunization of virgin cows with surface antigen TF1.17 of Tritrichomonas foetus. Infect. Immun. 61:1385-1394.

BonDurant R.H., Campero C.M., Anderson M.L. \& Van Hoosear K.A. 2003. Detection of Tritrichomonas foetus by polymerase chain reaction in cultured isolates, cervicovaginal mucus, and formalinfixed tissues from infected heifers and fetuses. J. Vet. Diagn. Invest. 15:579-584.

Bouters R., DeKeyser J., Vandeplassche M., Van Aert A., Brone E. \& Bonte P. 1973. Vibrio fetus infection in bulls: curative and preventive vaccination. Brit. Vet. J. 129:52-57.

Brooks B.W., Devenish J., LutzeWallace C.L., Milnes D., Robertson R.H. \& Berlie-Surujballi G. 2004. Evaluation of a monoclonal antibodybased enzyme-linked immunosorbent assay for detection of Campylobacter fetus in bovine preputial washing and vaginal mucus samples. Vet. Microbiol. 103(1/2)77-84.

Bryner J.H. 1990 Bovine abortion caused by Campylobacter fetus, p.70-81. In: Kirkbride C.A. (Ed.), Laboratory Diagnosis of Livestock Abortion in Food Animals. Iowa State University Press, Ames.

Campero C.M., Dubra C.R., Bolondi A., Cacciato C., Cobo E., Perez S., Odeon A., Cipolla A. \& BonDurant R.H. 2003. Two-step (culture and PCR) diagnostic approach for differentiation of non- $T$. foetus trichomonads from genitalia of virgin beef bulls in Argentina. Vet. Parasitol. 112:167-175.

Cipolla A.L., Casaro A.P., Terzolo H.R. Estela E.S., Brooks B.W. \& 
Garcia M.M. 1994. Persistence of Campylobacter fetus subsp. venerealis in experimentally infected heifers. Vet. Rec. 134:628.

Clark B.L. 1971. Review of bovine vibriosis. Aust. Vet. J. 47:103-107.

Clark B.L., Dufty J.H., Monsbourgh M.J. \& Parsonson I.M. 1974. Immunization against bovine vibriosis vaccination of bulls against infection with Campylobacter fetus subsp. venerealis. Aust. Vet. J. 50:407-409.

Clark B.L., Dufty J.H. \& Parsonson I.M. 1983. Immunisation of bulls against trichomoniasis. Aust. Vet. J. 60:178-179.

Clark B.L., Emery D.L. \& Dufty J.H. 1984. Therapeutic immunisation of bulls with the membranes and glycoproteins of Tritrichomonas foetus var. brisbane. Aust. Vet. J. 61:65-66.

Cobo E.R., Morsella C., Cano D., Cipolla A. \& Campero C.M. 2004. Immunization in heifers with dual vaccines containing Tritrichomonas foetus and Campylobacter fetus antigens using systemic and mucosal routes. Theriogenol. 62:1367-1382.

Cobo E.R., Corbeil L.B., Gershwin L.J. \& BonDurant R.H. 2009. Preputial cellular and antibody responses of bulls vaccinated and/or challenged with Tritrichomonas foetus. Vaccine 28:361-370.

Corbeil L.B. 1999. Immunization and diagnosis in bovine reproductive tract infections. Adv. Vet. Med. 41:217-239.

Corbeil L.B., Anderson M.L., Corbeil R.R., Eddow J.M. \& BonDurant R. H. 1998. Female reproductive tract immunity in bovine trichomoniasis. Am. J. Reprod. Immunol. 39:189-198.

D’Apice M. 1956. Ocorrência do aborto no Estado de São Paulo devido ao Vibrio fetus. Biológico, São Paulo, 22:15-18.

Dekeyser J. 1984. Bovine genital campylobacteriosis, p.181-191. In: Butzler J.P. (Ed.), Campylobacter infection in man and animal. CRC Press, Boca Raton, Florida.

Eaglesome M.D. \& Garcia M.M. 1997. Disease risks to animal health from artificial insemination with bovine semen. Rev. Sci. Tech. 16:215-225.

Eaglesome M.D., Garcia M.M., Hawkins C.F. \& Alexander F.C. 1986. Vaccination studies for the control of Campylobacteriosis in Jamaican cattle. Vet. Rec. 119:299-301.

Fernandes J.C.T. \& Gomes M.J.P. 1992. Campilobacteriose bovina, p.141-150. In: Charles T.P. \& Furlong J. (Eds), Doenças dos Bovinos de Leite Adultos. Embrapa-CNPGL, Coronel Pacheco.

Figueiredo J.F., Pellegrin A.O., Fóscolo C.B., Machado R.P., Miranda K.L. \& Lage A.P. 2002. Evaluation of direct immunofluorescent antibody test for the diagnosis of bovine genital Campylobacteriosis. Revta Latino Am. Microbiol. 44:118-123.

Fóscolo C.B., Pellegrin A.O., Leite R.C., Stynen A.P. \& Lage A.P. 2005. Vaccination of bulls against bovine genital campylobacteriosis: $A$ therapeutic approach. Anim. Reprod. 2(2):122-127.

Genovez M.E., Scarcelli E. \& Picone A.B.B. 1986. Avaliação de dois métodos de coleta de muco prepucial no diagnóstico da campilobacteriose genital em touros. Biológico, São Paulo, 52:7-11.

Gomes M.J.P., Fernandes J.C.T. \& Silva C.E. 1991. Identificação de Tritrichomonas foetus em bovinos no estado do Rio Grande do Sul. Arq. Fac. Vet. UFRGS 19:103-111.

Goodger W.J. \& Skirrow S.Z. 1986. Epidemiologic and economic analysis of an unusually long epizootic of trichomoniasis in a large California dairy herd. J. Am. Vet. Med. Assoc. 189:772-776.

Granger B.L., Warwood S.J., Benchimol M. \& Souza W. 2000. Transiente invagination of flagella by Tritrichomonas foetus. Parasitol. Res. 86:699-709.

Guest G.B. 1988. Extra label policy update. FDA Vet. 3:5-6.

Guida H.C., Medeiros P.M. \& Pizelli G.N. 1960. Conservação do Trichomonas foetus no meio de Rieck modificado. Instituto de Zootecnia 35:1-7.

Hewson P.I., Lander K.P. \& Gill K.P.W. 1985. Enzyme-linked immuno- sorbent assay for antibodies to Campylobacter fetus in bovine vaginal mucus. Res. Vet. Sci. 38:41-45.

Hidalgo M.A., Cordova L.F. \& Jochle W. 1970. A simplified treatment of trichomoniasis in the bull. Vet. Rec. 87:161-163.

Hum S., Quinn C. \& Kennedy D. 1994. Diagnosis of bovine veneral campylobacteriosis by ELISA. Aust. Vet. J. 71:140-143.

Hum S., Quinn K., Brunner J. \& On S.L.W. 1997. Evaluation of a PCR assay for identification and differentiation of Campylobacter fetus subspecies. Aust. Vet. J. 75:827-831.

Jesus V.L.T., Guida H.G., Andrade V.L.B., Serra-Freire M.N., Ramos A.A. \& Pereira E.B.B. 1996. Comparação entre o uso de tripaflavina e dimetridazole no tratamento da tricomonose bovina. Pesq. Vet. Bras. 16:49-51.

Jesus V.L.T., Pereira M.J.S., Alves P.A.M. \& Fonseca A.H. 2004. Fatores intrínsecos do hospedeiro associados à prevalência de Tricomonose genital bovina. Revta Bras. Parasitol. Vet. 13(4):159163.

Kvasnicka W.G., Hanks D., Huang J.C., Hall M.R., Sandblom D., Chu H.J., Chavez L. \& Acree W.M. 1992. Clinical evaluation of the efficacy of inoculating cattle with a vaccine containing Tritrichomonas foetus. Am J. Vet. Res. 53(11):2023-2027.

Kvasnicka W.G., Hall M. \& Hanks D. 1996. Current concepts in the control of bovine trichomoniasis. Compend. Cont. Educ. Pract. Vet. 18:S105-S111.

Lage A.P. 2001. Epidemiologia e controle da campilobacteriose genital bovina. Simpósio Pfizer sobre Doenças Infecciosas e Vacinas para Bovinos, São Paulo, p.17-25.

Lage A.P. \& Leite R.C. 2000. Campilobacteriose genital bovina (Vibriose). Pecuária de Corte 10:50-54.

Lage A.P., Carvalho A.C.T. \& Leite R.C. 1992. Comparison of procedures for isolating Campylobacter sp from diarrheic and normal calves. Revta Microbiol. 23:151-154.

Lander K.P. 1990. The application of a transport and enrichment medium to the diagnosis of Campylobacter fetus infections in bulls. Br. Vet. J. 146(4):334-340.

Leite R.C. 1977. Avaliação de alguns métodos de diagnóstico e análise custo/benefício do controle da campilobacteriose bovina. Dissertação de Mestrado em Medicina Veterinária Preventiva, Escola de Veterinária, Universidade Federal de Minas Gerais, Belo Horizonte, MG. 38p.

Leite R.C., Reis R. \& Rivera F.E.B. 1980. Controle da vibriose bovina através da vacinação. Arqs Esc. Vet. UFMG 32:259-264.

Leite R.C., Pellegrin A.O., Martins N.E., Silva N., Gomes L.I., Costa G.M., Reinato A.P.R., Guimarães P.H.S. \& Lage A.P. 1997. Tricomonose bovina: diagnósticos realizados na Escola de Veterinária da UFMG no período de 1979 a 1995. Revta Bras. Reprod. Anim. 21(2)166-168.

McCool C.J., Townsend M.P., Wolfe S.G., Simpson M.A., Olm T.C., Jayawardhana G.A. \& Carney J.V. 1988. Prevalence of bovine venereal disease in the Victoria River District of the Northern Territory: Likely economic effects and practicable control measures. Aust. Vet. J. 65:153-156.

McLoughlin D.K. 1970. Dimetridazole, a systemic treatment for bovine venereal trichomoniasis. III. Trials with cows. J. Parasitol. 56:39-40.

McMillen L. \& Lew A.E. 2006. Improved detection of Tritrichomonas foetus in bovine diagnostic specimens using a novel probe-based real time PCR assay. Vet Parasitol. 141:204-215.

McMillen L., Fordyce G., Doogan V.J. \& Lew A.E. 2006. Comparison of culture and a novel $5^{\prime}$ Taq nuclease assay for direct detection of Campylobacter fetus subsp. venerealis in clinical specimens from cattle. J. Clin. Microbiol. 44(3):938-945.

Medeiros P.M. \& Figueiredo J.B. 1971. Trichomonose bovina em Minas Gerais. Arqs Esc. Vet. UFMG 23:143-147. 
Megale F. 1963. Identificação do Trichomonas foetus em Minas Gerais (Comunicação científica). Arq. Esc. Vet. UFMG 15:405.

Mello M.H. 1954. Dados sobre a incidência de tricomonose bovina em alguns estados do Brasil. Bolm Insem. Artif., Rio de J., 6:16-23.

Miranda K.L. 2005. Prevalência da campilobacteriose genital bovina em touros de corte em alguns estados brasileiros em 2000. Dissertação de Mestrado em Medicina Veterinária Preventiva, Universidade Federal de Minas Gerais, Belo Horizonte, MG. 47p.

Ogra P.L.1996. Mucosal immunoprophilaxis: An introductory overview, p.3-14. In: Kiyono H., Ogra P.L. \& McGhee J.R. (Eds), Mucosal Vaccines. Academic Press, San Diego. 479p.

OIE 2009. Bovine genital campylobacteriosis and Trichomonosis. World Organization for Animal Health. Disponível em: http://www.oie.int/ wahis/public.php?page=disease_timelines. Acesso em 10 dez 2009.

Palladino M.R., Campero C.M. \& Villar J.A. 1982. Resistencia de Trichomonas foetus a tricomonicidas. Gaceta Vet. 44:400-406.

Parsonson I.M., Clark B.L. \& Dufty J.H. 1976. Early pathogenesis and pathology of Tritrichomonas foetus in infection in virgin heifers. J. Comp. Pathol. 86:59-66.

Pellegrin A.O., Sereno J.R.B., Leite R.C. \& Costa G.M. 1998. Campilobacteriose genital bovina em touros do Mato Grosso do Sul. Revta Bras. Reprod. Anim. 21(1):43-46.

Pellegrin A.O., Lage A.P., Sereno J.B., Ravaglia E., Costa M.S. \& Leite R.C. 2002. Bovine Genital Campylobacteriosis in Pantanal, Mato Grosso do Sul State, Brazil. Rev. Élev. Méd. Vét. Pays Trop. 55(3)160-173.

Rae D.O. \& Crews J.E. 2006. Tritrichomonas foetus. Vet. Clin. Food Anim. 22:595-611.

Rae D.O., Chenoweth P.J., Genho P.C., McIntosh A.D., Crosby C.E. \& Moore S.A. 1999. Prevalence of Tritrichomonas fetus in a bull population and effect on production in a large cow-calf enterprise. J. Am. Vet. Med. Assoc. 214:1051-1055.

Ramos A.A., Leite M.L.A.S., Guida H.G., Machado R.D., Andrade V.L.B., Jesus V.L.T. \& Camargo A.J.R. 1986. Eficiência de uma vacina contra a campilobacteriose bovina com culturas autóctones em adjuvante oleoso. Pesq. Vet. Bras. 6:15-21.

Rhyan J.C., Stackhousaen L.L. \& Quinn W.J. 1988. Fetal and placental lesions in bovine abortion due to Tritrichomonas foetus. Vet. Pathol. 25:350-355.

Rhyan J.C., Blanchard P.C., Kvasnicka W.G., Hall M.R., Hanks D. 1995. Tissue-invasive Tritrichomonas foetus in four aborted bovine fetuses. J. Vet. Diagn. Invest. 7:409-412.

Rocha F.S., Jesus V.L.T., Torres H.M., Gomes M.J.P., Figueiredo M.J., Nascimento E.R., Ferreira T. \& Aquino M.H.C. 2009. Investigação de Campylobacter fetus e Tritrichomonas foetus na mucosa prepucial de touros da região do Médio Paraíba, RJ. Ciência Rural 39:1587-1590.
Roehe R. 1948. Tricomoniase bovina. Bolm Direct. Prod. Anim. 3(6):21-26.

Sanderson M.W. \& Gnad D.P. 2002. Biosecurity for reproductive diseases. Vet. Clin. Food Anim. 18:79-98.

Seger C.L., Lank R.B. \& Levy H. 1966. Dihydrostreptomycin for treatment of genital vibriosis in the bull. J. Am. Vet. Med. Assoc. 149:16341639.

SINDAN 2010. Compêndio de Produtos Veterinários. Sindicato Nacional da Indústria de Produtos para Saúde Animal. Disponível em http://www.cpvs.com.br/cpvs/index.html. Acesso em 17 de junho de 2010.

Skirrow S.Z. \& BonDurant R.H. 1988. Bovine trichomoniasis. Vet. Bull. 58(8):591-603.

Skirrow S., Bondurant R., Farley J. \& Correa J. 1985. Efficacy of ipronidazole against trichomoniasis in beef bulls. J. Am. Vet. Med. Ass. 187:405-407.

Stoessel F. 1982. Las Enfermedades Venereas de los Bovinos: trichomoniasis y vibriosis genital. Zaragoza, Acribia. 163p.

Stynen A.P.R., Pellegrin A.O., Fóscolo C.B., Figueiredo J.F., Canella Filho C., Leite R.C. \& Lage A.P. 2003. Campilobacteriose genital bovina em rebanhos leiteiros com problemas reprodutivos da microrregião de Varginha, Minas Gerais. Arq. Bras. Med. Vet. Zootec. 55:766-769.

Thompson S.A \& Blaser M.J. 2000. Pathogenesis of Campylobacter fetus infections, p.321-347. In: Nachamkin I. \& Blaser M.J. (Eds), Campylobacter. $2^{\text {nd }}$ ed. ASM, Washington.

Van Aert A., Dekeyser P., Brone E., Bouters R. \& Vandeplassche M. 1976. Nature of antibodies to Campylobacter fetus in preputial secretions from a vaccinated bulls. Brit. Vet. J. 132:615-620.

Vandamme P. 2000. Taxonomy of the family Campylobacteraceae, p.3-20. In: Nachamking N. \& Blaser M.J. (Eds), Campylobacter. $2^{\text {nd }}$ ed. American Society for Microbiology, Washington.

Vargas A.C., Costa M.M., Vainstein M.H., Kreutz L.C. \& Neves J. P. 2003. Phenotypic and molecular characterization of bovine Campylobacter fetus strains isolated in Brazil. Vet. Microbiol. 19:121-132.

Vasquez L.A., Ball L., Bennett B.W., Rupp G.P., Ellis R., Olson J.D. \& Huffman M.H. 1983. Bovine genital campilobacteriosis (Vibriosis): Vaccination of experimentally infected bulls. Am. J. Vet. Res. 44:1553-1557.

Villarroel A., Carpenter T.E. \& BonDurant R.H. 2004. Development of a simulation model to evaluate the effect of vaccination against Tritrichomonas foetus on reproductive efficiency in beef herds. Am. J. Vet. Res. 65:770-775.

Wagner W.C., Dunn H.O. \& Van Vleck L.D. 1965. Incidence of Vibrio fetus in an A.I. stud. Cornell Vet. 55:209-220. 